\author{
EVS27 \\ Barcelona, Spain, November 17-20, 2013
}

\title{
Lightweighting of a Hydrogen Fuel Cell Vehicle Whilst Meeting Urban Accident Criteria
}

\author{
O. Grimes ${ }^{1}$, C. Bastien ${ }^{1}$, J. Christensen ${ }^{1}$, N. Rawlins ${ }^{1}$, W. Hammond ${ }^{1}$, P. Bell ${ }^{1}$, \\ B. Brown ${ }^{1,}$ J. Beal ${ }^{1}$ \\ ${ }^{1}$ Coventry University, Priory street, Coventry CV1 5FB, christophe.bastien@coventry.ac.uk
}

\begin{abstract}
The aim of this paper is to assess the safety performance of a lightweight hydrogen fuel cell city concept vehicle entitled Microcab [1]. The Microcab is a lightweight 4 seat hydrogen fuel cell concept vehicle with a combined mass (excluding passengers) of less than $800 \mathrm{~kg}$. The Microcab has a range of $180 \mathrm{miles}$; it includes a hydrogen fuel tank pressurised to 350 bar. The research focuses on urban accident scenarios; including frontal, lateral and compatibility loadcases. All loadcases utilise urban speeds, i.e. speeds ranging up to $40 \mathrm{~km} / \mathrm{h}$ for frontal impacts.

The crashworthiness of the Microcab has been analysed using explicit non-linear Finite Element Analysis (FEA). The study concludes that within the limitations of the material parameter definitions and mass distributions; the crashworthiness in connection with urban accident scenarios is good. This includes aspects such as vehicle compatibility loadcases and protection of the hydrogen fuel tank e.g. for intrusion. The outcome of the study also suggests structural refinements for the future Microcab final production model; with an aim of further improving the vehicles' crashworthiness. These refinements include raising the primary front crash structure to better align it with that of a Sports Utility Vehicle (SUV) as well as bracing the fuel cell area in case of a rear impact in order to better protect this vital component. It is also suggested that adhesive joints were suitable for structural crash integrity in all the loadcases studied within this paper, including low speed impact for repairability.

A structural optimisation study has also been undertaken utilising Design Of Experiments (DOE), shapesize- and topology optimisation. DOE was employed to further improve the stiffness of the chassis with respect to safety, whilst minimising the mass increase. Topology optimisation models based on the maximum crash force magnitudes computed in the initial part of the study were also setup; the results of these suggested future changes to the Microcabs' floor layout could be utilised to further enhance the vehicles crashworthiness.
\end{abstract}

Keywords: EV, Hydrogen Fuel Cell, crashworthiness, Optimisation, Topology 


\section{Introduction}

The aim of this paper is to assess the safety performance of a lightweight hydrogen fuel cell city concept vehicle entitled Microcab [1]. The Microcab, illustrated in Figure 1, is a lightweight 4 seat hydrogen fuel cell concept vehicle with a combined mass (excluding passengers) of less than $800 \mathrm{~kg}$. The Microcab has a range of 180 miles; it includes a hydrogen fuel tank pressurised to 350 bar.

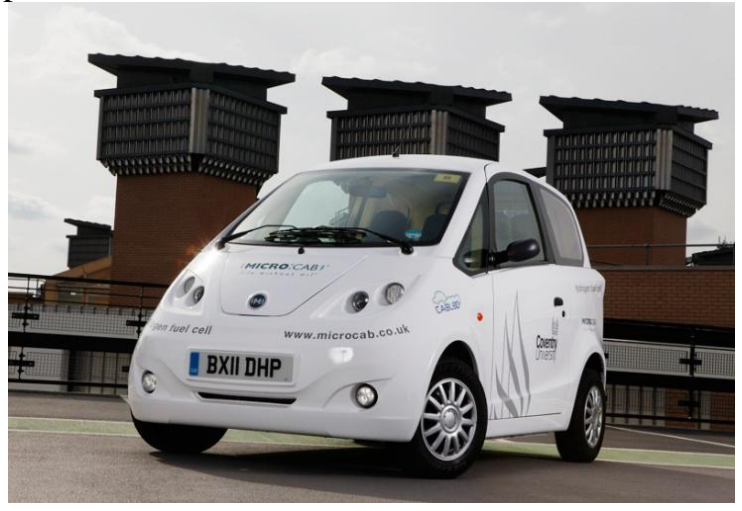

Figure 1: Microcab. Concept Lightweight Hydrogen Fuel Cell Vehicle

The Microcab prototype chassis has previously been studied in isolation. The study documented by this paper did however include the full detail of the vehicle, including e.g. door and body panels. This increased level of detail enabled a significantly increased understanding of the possibilities for further light-weighting of the vehicle ahead of a future commercial production of the Microcab.

The future hydrogen fuel cell vehicle, which will follow the current Microcab concept vehicle, will be engineered considering the lightweighting performance of this prototype whilst further enhancing the structural integrity of the vehicle. There are currently no dedicated EuroNCAP test requirements for such lightweight vehicles and few obligatory legal requirements for such low volume productions, hence it was decided that the safety assessment criteria would be based on "typical" urban impact scenarios.

\section{Vehicle Safety Assessment}

The purpose of this section is to evaluate the overall crashworthiness of the current Microcab. Before this can be completed it was necessary to define the safety requirements for the Microcab, or indeed any similar lightweight vehicle operating in an urban environment. This was done using statistics from the FARS database which contains data on all vehicle crashes in the United States that occurred on a public roadway and involved a fatality [2]. The overall results obtained from the database are illustrated in Figure 2 , which indicates the likely severity of different impact scenarios.

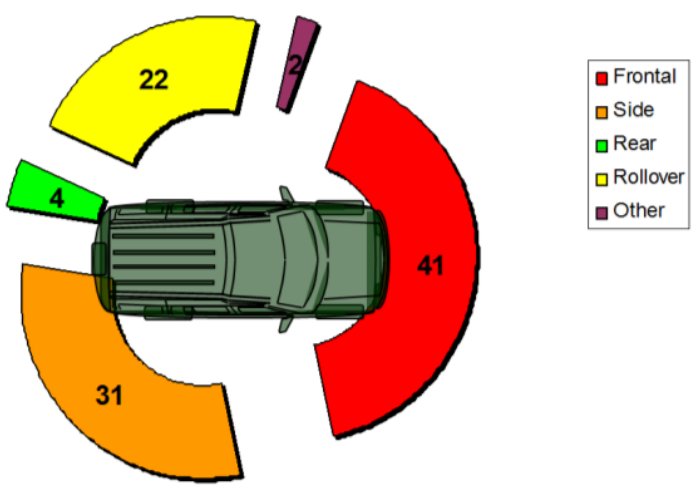

Figure 2: Severity of accident types as percentages (FARS database)

Based on the overall distribution of accidents, as indicated in Figure 2, it was chosen that the study would primarily focus on two types of impact; namely front and rear impact scenarios. The front scenario was chosen due to its severity as indicated in Figure 2. The rear scenario was primarily chosen due to the fact that the Microcab has a fuel cell installed towards the rear-end of the vehicle and forward of that, a high pressure fuel tank, which is a potential safety concern. Aside from the "conventional" front and rear impact scenarios the front impact scenarios were to include aspects of vehicle compatibility; whilst the rear impact scenarios were to include details of the potential deformation in the vicinity of the high pressure fuel tank.

In order to complete the safety assessments a Finite Element (FE) model of the Microcab was created; the overall details of the model are listed in Table 1; the model is illustrated in Figure 3 and Figure 4.

Table 1: MicrocabFE model parameters

\begin{tabular}{|l|l|}
\hline Number of nodes & $1,737,816$ \\
\hline Number of elements & $1,625,252$ \\
\hline Element average size (mm) & 5 \\
\hline Model Timestep (s) & $0.7 \mathrm{E}-6$ \\
\hline Mass scaling (\%) & 0.63 \\
\hline
\end{tabular}




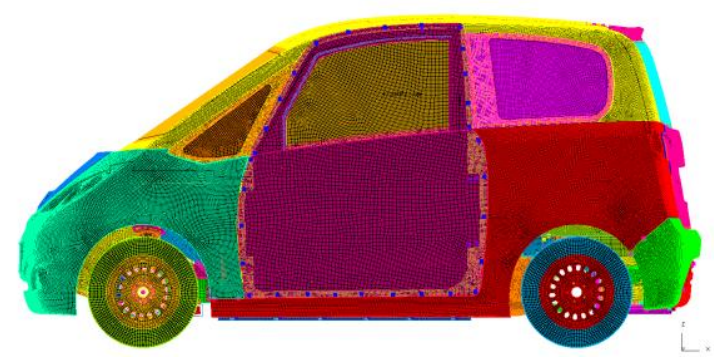

Figure 3: Discretised Microcab (FE) model (panels)

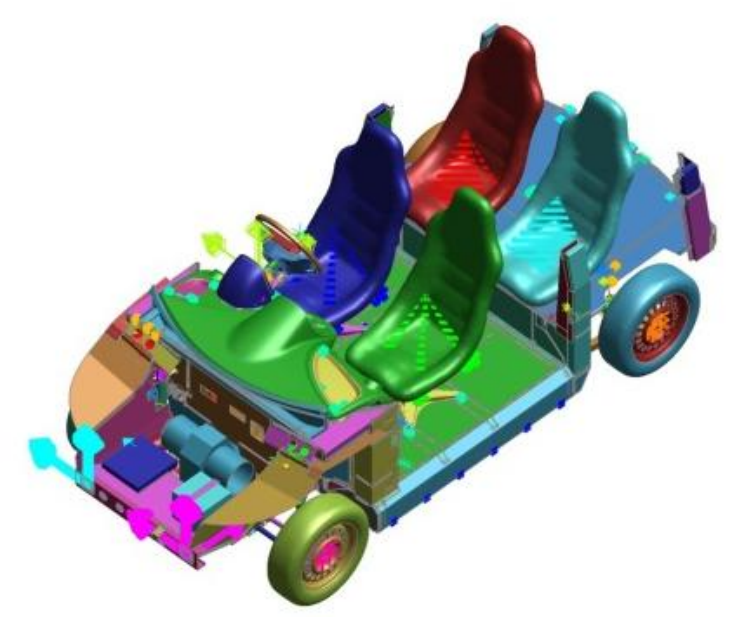

Figure 4: Discretised Microcab (FE) model (chassis)

As not all material properties were readily available it was necessary to estimate some of these using the Cambridge Engineering Selector (CES) database. The general material properties used for the FE models are listed in Table 2.

Table 2: Microcab material properties

\begin{tabular}{|c|c|c|c|}
\hline Material & E (MPa) & $\begin{array}{c}\text { Yield } \\
(\mathrm{MPa})\end{array}$ & $\begin{array}{c}\text { Etan } \\
(\mathrm{MPa})\end{array}$ \\
\hline Alum. & 70,000 & 70 & 1,000 \\
\hline GRP & 20,000 & 20 & 500 \\
\hline Adhesive & 3,000 & N/A & N/A \\
\hline Steel & 210,000 & 250 & 1,000 \\
\hline
\end{tabular}

It was not possible to verify if the Microcab prototype vehicles' material characteristics corresponded exactly to those listed in Table 2.

\subsection{Frontal Impact}

Inner city and suburban accidents cover a wide spectrum of crash scenarios, most of which occur at low speeds inferior of $40 \mathrm{~km} / \mathrm{h}(25 \mathrm{mph})$ [3]. One of the most common accident scenarios is an impact into the rear of a stationary vehicle [3].
In such scenarios it is known that the shape and stiffness of the (stationary) target vehicle has a great influence on the (moving) bullet vehicle. It can be shown that the bumper height and stiffness of the target vehicle has an influence on the bullet vehicles' impact response [5]. Figure 5 illustrates different types of target vehicles impacted by the same bullet vehicle (the Chrysler / Dodge Neon).

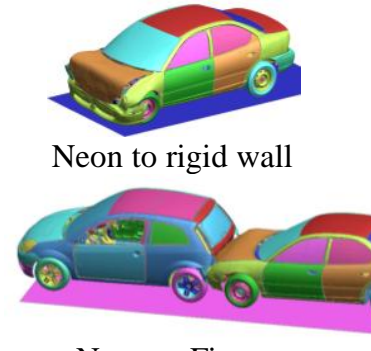

Neon to Fiesta
Neon to Neon

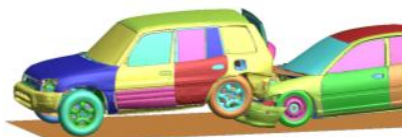

Neon to Rav4

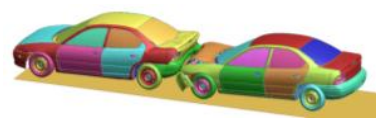

Figure 5: Examples of bullet vehicle to target vehicle impacts

The crash pulses associated with the 4 impact scenarios illustrated in Figure 5, completed at an initial impact speed of $40 \mathrm{~km} / \mathrm{h}$, are shown in Figure 5.

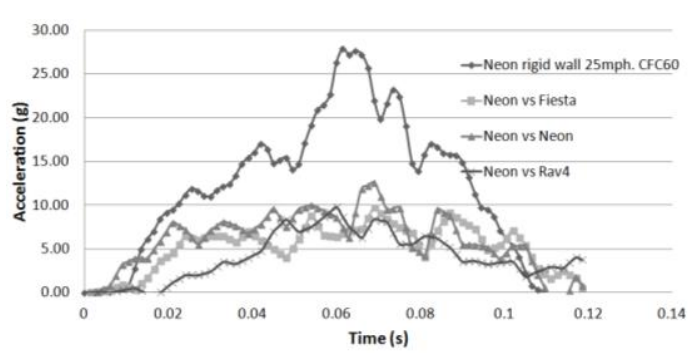

Figure 6: Crash pulse for $40 \mathrm{~km} / \mathrm{h}$ impacts illustrated in Figure 5

As indicated by Figure 6; a direct impact on a rigid surface provides 3 times the structural load than for a vehicle to vehicle collision with an initial impact speed of $40 \mathrm{~km} / \mathrm{h}$ [5]. Consequently, the vehicle to rigid wall scenario is the loadcase which will be applied to the Microcab. The resulting crash pulse from the above described scenario is illustrated in Figure 7. 


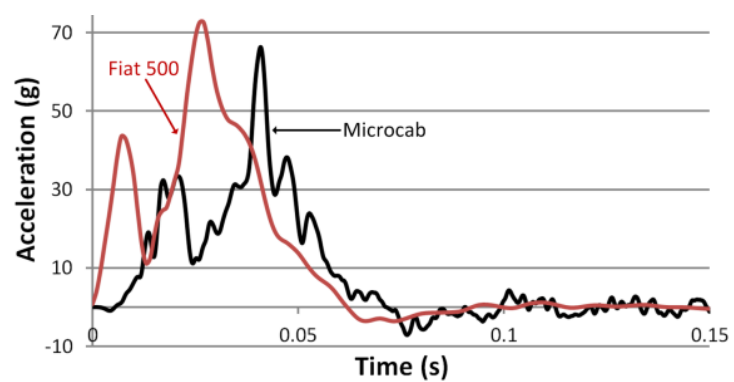

Figure 7: Microcab and Fiat 500 crash pulse against rigid wall at $40 \mathrm{~km} / \mathrm{h}$

The Microcab concept vehicle crash pulse shape and magnitude of Figure 7 is comparable to a certified standard Fiat 500 US-NCAP rigid barrier test $(54 \mathrm{~km} / \mathrm{h})$ also displayed in Figure 7 [4]. Due to the intended operating environment of the Microcab being urban it is reasonable to compare the crash pulse of the $40 \mathrm{~km} / \mathrm{h}$ Microcab impact to the $54 \mathrm{~km} / \mathrm{h}$ impact of the Fiat 500 . It can therefore be concluded that the Microcab's front-end architecture is adequate for city frontal impacts and that it architecture is fit for purpose. Figure 8 illustrates the Microcab impacting a rigid wall at $40 \mathrm{~km} / \mathrm{h}$.

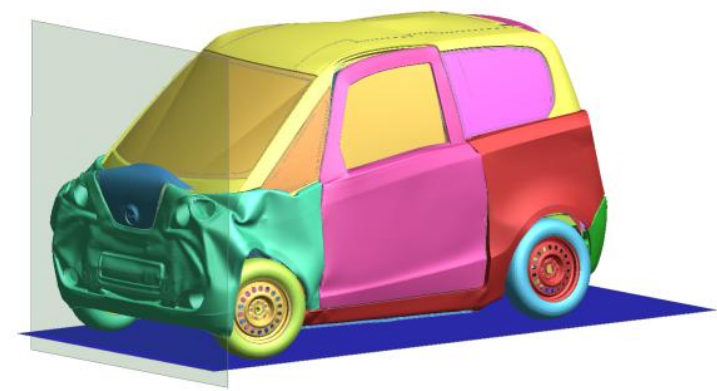

Figure 8: Microcab impacting rigid wall at $40 \mathrm{~km} / \mathrm{h}$

In Figure 8 it is worth noticing that the passenger cell remains intact, thus substantiating the conclusion drawn above.

As indicated by Figure 7 and Figure 8, the Microcab concept vehicle absorbs its own kinetic energy whilst keeping the occupant compartment intact during the $40 \mathrm{~km} / \mathrm{h}$ impact with the rigid wall. The primary front structure originally collapses generating a deceleration level of $30 \mathrm{~g}$ in the first $20 \mathrm{~ms}$, while the rest of the front-end buckles and seizes at around $40 \mathrm{~ms}$, creating a maximum deceleration level of $66 \mathrm{~g}$.

\subsection{Rear impact and fuel cell protection}

As previously mentioned the high pressure fuel tank is an aspect of particular interest with respect to rear impact scenarios. In order to analyse this event the Microcab became the target vehicle in a static un-braked position. Subsequently it was impacted by the bullet vehicle; the impact energy was transformed into deformation as well as kinetic energy. The bullet vehicle was set to be a Sports Utility Vehicle (SUV), in this case a Toyota Rav4, primarily due to its greater mass (when compared to the other vehicle models available; the Ford Fiesta or the Neon).

The structural integrity of the fuel cell and hydrogen tank were assessed using a reduced vehicle model for the Microcab and a $1500 \mathrm{~kg}$ rigid plane travelling at $40 \mathrm{~km} / \mathrm{h}$ representing the Rav4, as illustrated in Figure 9. The reason for reducing the model was to decrease the Central Processing Unit (CPU) runtime.

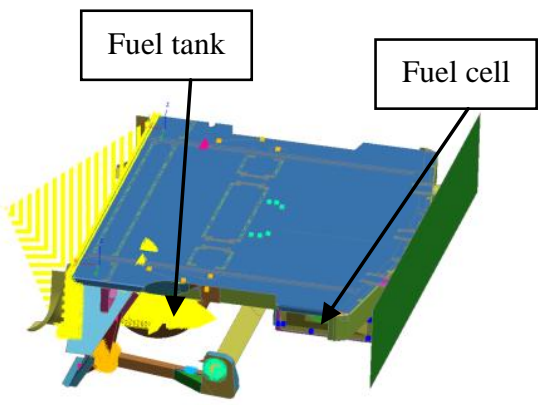

Figure 9: Reduced Microcab rear end structure (top view).

The reduced model included the rear end of the Microcab as well as a mass element representing the mass and inertia tensors of the removed Microcab structure. The model was un-braked, hence when the rigid plane impacts the structure will be accelerated forwards and deformations of the structure will also occur.

Reviewing the results obtained from this reduced model it was observed that the fuel tank remained intact throughout the impact scenario. The bumper beam and the fuel cell guard were however found to be crushing the fuel cell, as illustrated in Figure 10. 


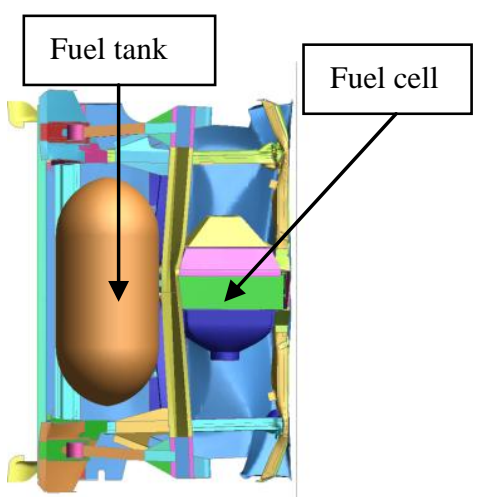

Figure 10: Integrity of fuel cell and hydrogen tank (bottom view)

The results also revealed that the rear longitudinal joints crushed more than anticipated, allowing the rear bumper beam to intrude the fuel cell space and make contact with it. The fuel cell deformation energy is plotted in Figure 11.

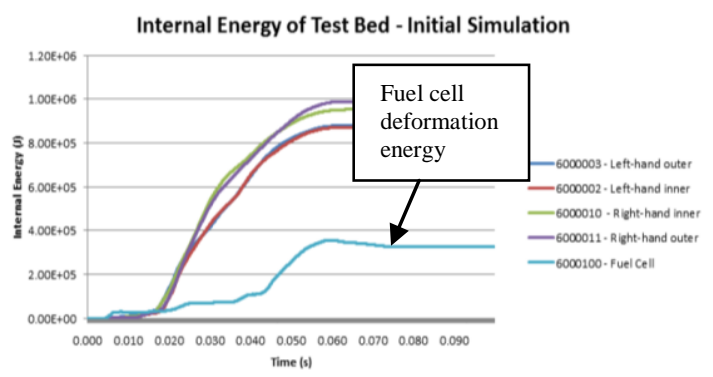

Figure 11: Fuel cell deformation energy levels (original configuration)

As illustrated by Figure 11, the rear impact transmitted peak value of $38 \mathrm{e} 5 \mathrm{~mJ}$ of energy onto the fuel cell structure. Consequently, a refinement of the sacrificial rear crash structure which transfers the bullet vehicle's kinetic energy thereby minimising the bullet vehicles structural damage was required.

In this context a curved spacer was engineered and subsequently optimised using Design Of Experiments (DOE) with a response surface based on HyperKriging, in order to determine the ideal curvature and gauge thickness. The fuel cell crash spacer was curved due to packaging requirements, and is illustrated in Figure 12.

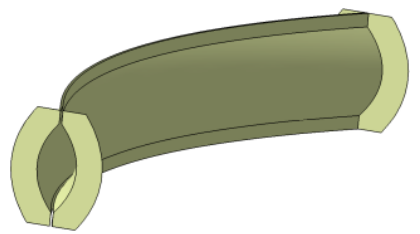

Figure 12: Fuel cell crash spacer
Additional HyperKriging optimisation was also employed to obtain the ideal gauge thickness for the rear longitudinal, in addition to the sizing of the fuel cell crash spacer. The objective of all of the above mentioned optimisations was to minimise the peak deformation energy transferred to the fuel cell subject to the constraint of a minimal amount of added structural mass. The resulting optimised rear crash structure is illustrated in Figure 13.
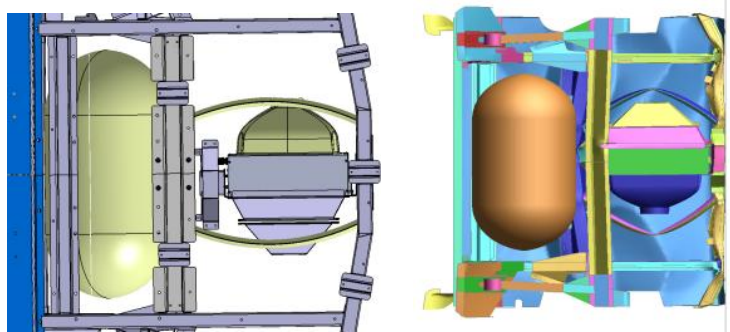

Figure 13: Optimised fuel cell crash solution

Based on the optimised crash structure displayed in Figure 13, the rear impact scenario was repeated; the resulting fuel cell deformation energy levels can be seen in Figure 14.

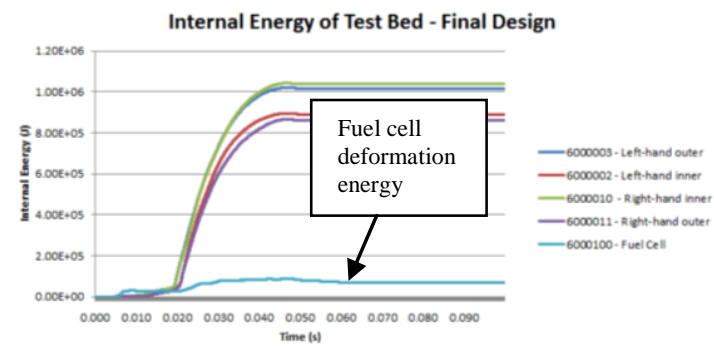

Figure 14: Fuel cell deformation energy levels optimised configuration

By comparing Figure 14 to Figure 11, it can be seen that the fuel cell deformation levels have generally decreased significantly. The maximum energy transferred via the optimised crash structure was now $10 \mathrm{e} 5 \mathrm{~mJ}$; i.e. to 3.8 time less than that of the original vehicle concept, Figure 11. Consequently the structural damage was also significantly reduced.

\subsection{Compatibility}

As discussed in the introduction, this paper will study the compatibility accident level of the Microcab concept vehicle.

Vehicle compatibility refers to the tendency of some vehicles to inflict more damage on another vehicle in two-car crashes, due difference of masses or misalignment of crash structures. The 
height (from the ground) of the front crash structure of an SUV is typically larger than that of a smaller vehicle such as the Microcab. This misalignment can have a significant effect in the event of an accident or impact. An example of this misalignment can be seen in Figure 15, where the front longitudinals of the Toyota Rav4 are clearly not aligned with those of the Microcab.

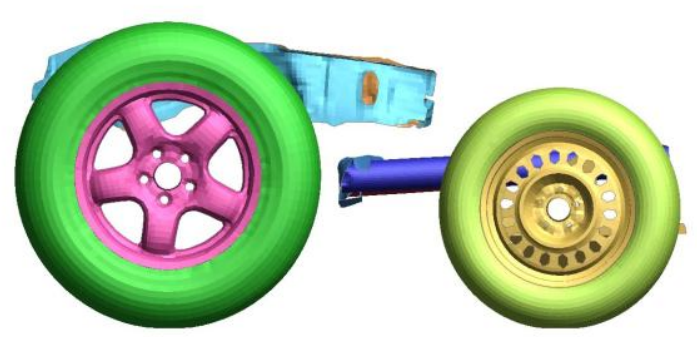

Figure 15: Toyota Rav4 and Microcab concept model front crash structure misalignment

Assessing the compatibility of a vehicle is not a legislative requirement, and is not considered in EuroNCAP testing. Nevertheless, this part of the paper considers the fuel cell and fuel tank integrity as well as opportunities of assessing the integrity of the cabin. Using the UTAC (Technical Union for the Automobile, Motorcycle and Cycle industries) Progressive Deformable Barrier (PDB) for compatibility assessment (PDB), the aggressiveness of a vehicle can be found. The aggressiveness of a vehicle can be interpreted as an expression for the severity of the structural damage caused when two vehicles collide in a frontal impact. It was found that a $\mathbf{J}$ segment vehicle such as the Rav4 was the most aggressive vehicle, whilst the Microcab was found to have the same level of aggressiveness as a mid-sized vehicle such as the Ford Taurus, as indicated by Figure 16.

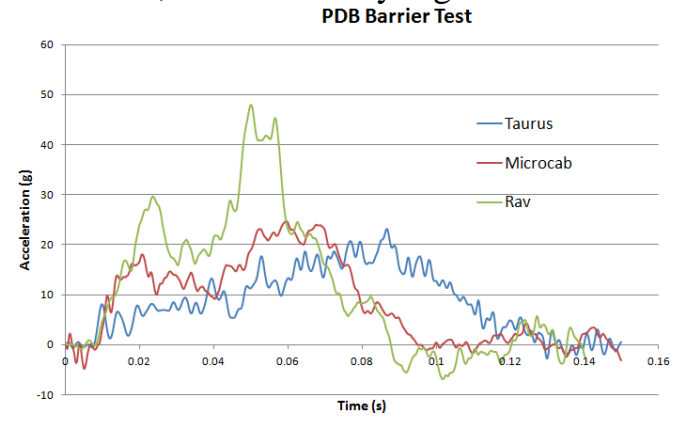

Figure 16: Comparison of compatibility aggressiveness
Due to its relatively high level of aggressiveness the Rav4 was chosen as the bullet vehicle to impact the Microcab in a frontal impact scenario, in order to assess the vehicle compatibility with an impact speed of $40 \mathrm{~km} / \mathrm{h}$.

The results of the initial front crash analysis indicated that the Microcab cabin resisted the impact from the Rav4, whilst the fuel cell and fuel tank both remained attached to the main body structure.

In order to enhance the crash compatibility of the Microcab concept vehicle the front-end crash structure was raised by $150 \mathrm{~mm}$ to better align the longitudinals with the Rav4, as they were not initially aligned, as illustrated in Figure 15.

With the height of the front crash structure of the Microcab increased the front impact scenario with the Rav4 was repeated, the resulting crash pulse is illustrated in Figure 17.

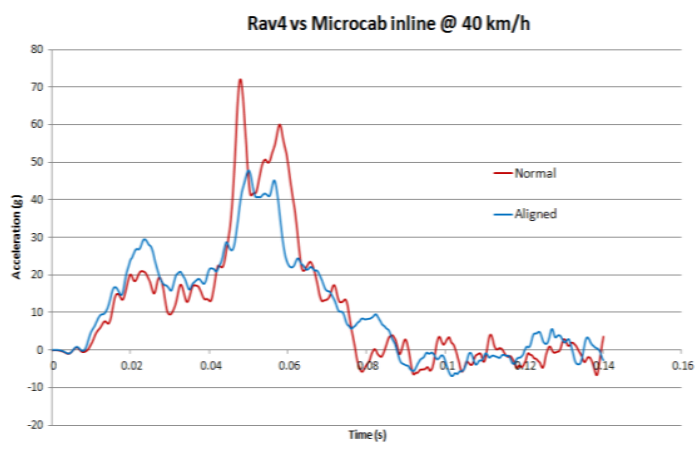

Figure 17: Microcab crash pulse before and after alignment of front crash structure to Rav4.

As indicated in Figure 17, raising the front-end crash structure of the Microcab suggests a vastly improved compatibility performance against an SUV; as the deceleration levels have reduced from $72 \mathrm{~g}$ to $48 \mathrm{~g}$, which is very likely to provide an improvement of the potential injuries of any vehicle occupants.

\subsection{Damageability}

Whereas the previous section considered the effects of medium to high speed impacts this section considers the effects of low speed impacts upon the Microcab structure. The test performed was an $8 \mathrm{~km} / \mathrm{h}$ rigid wall test based of the FMVSS215 [6] specification. This specifies the parameters of the crash test and stipulates that no permanent damage on the bumper cover or backup structure is allowed. 
Using FEA it was possible to extract plastic strains, Figure 18, which represent areas of the vehicle which have reached the elastic limit. In general plastic strain values above $4 \%$ indicates significant damage, i.e. failure to meet the FMVSS215 specifications.

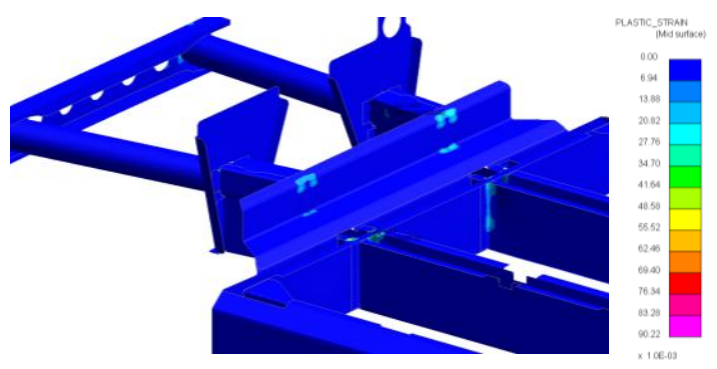

Figure 18: Microcab concept vehicle backup structure plastic strain levels

Based on the results displayed in Figure 18, it is suggested that the maximum level of plastic strain is located at the back of the crash structure, which only reaches a level of $3.5 \%$. This suggests that the concept vehicle is currently able to withstand a low speed impact without violating the FMVSS215 specifications.

In addition to the above, it was also ensured that a low speed bumper damage would not affect the vehicle crashworthiness performance should a subsequent $40 \mathrm{~km} / \mathrm{h}$ rigid wall impact follow, as illustrated in Figure 19.

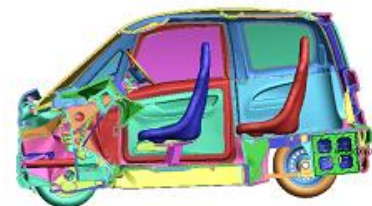

Original model

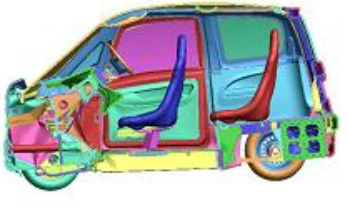

Repaired model
Figure 19: Microcab concept: Low speed damage against rigid wall does not affect front crash performance

\section{Structural Optimisation}

Based on the results of the crash analysis presented in this section, a comprehensive understanding of the vehicles crash structure and overall structural integrity was obtained; this highlighted areas of the structure which could be refined in the pursuit of enhanced crashworthiness and / or reduced vehicles mass.
This will be the focus of attention in the following section.

\subsection{Shape and sizing}

This part of the study investigated means of reducing force levels within the Microcab vehicle structure by finding the optimum section thickness whilst keeping the mass as low as possible. This study focused mostly on the frontal structure main components as illustrated in Figure 20.
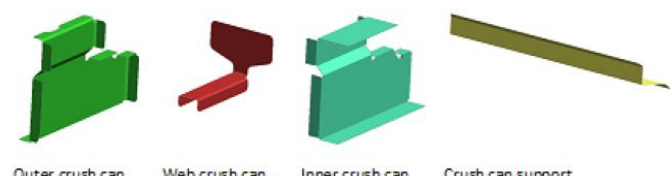

Figure 20: Components on which optimisation was undertaken

A DOE was performed, investigating panel gauge stiffness, which was modified with upper and lower bounds of $\pm 2 \mathrm{~mm}$ relative to their original thickness. This interval was primarily defined with respect to material and manufacturing costs in addition to overall vehicle mass.

After completing the optimisation study it was found that the inner crush can was the only component where the gauge thickness was reduced. All other components required an increase in thickness. The most significant increase was to the crash support section, Figure 20, where the gauge thickness increased from $3 \mathrm{~mm}$ to $5 \mathrm{~mm}$, indicating that this area would significantly benefit from reinforcing.

As a consequence, the acceleration response was improved, reducing the deceleration levels from $66 \mathrm{~g}$ to $46 \mathrm{~g}$, as illustrated in Figure 21.

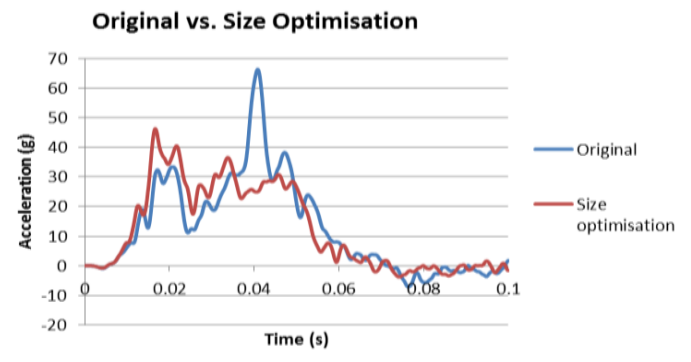

Figure 21: Microcab Concept vehicle: effect of floor member thickness size change

The outcome of the optimisation also led to an overall mass reduction of $1.1 \mathrm{~kg}$. 
By optimising the shape and size of the key components, Figure 20, it was observed that neither further mass savings nor significantly improved crash performance could be obtained, as the variation of structural mass was minute whilst the deceleration reduced by a maximum of $3 \mathrm{~g}$.

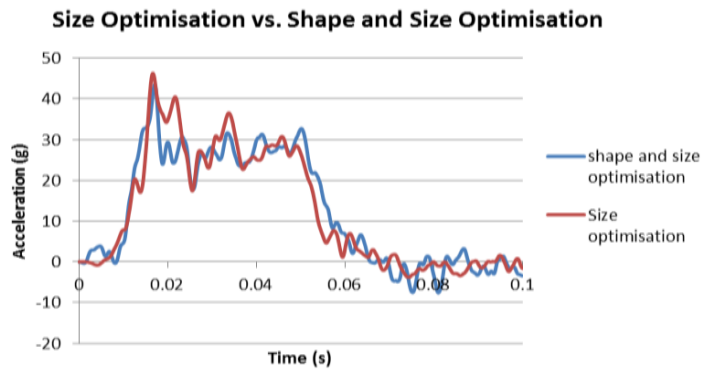

Figure 22: Comparison between pure sizing and shape/sizing combination

Consequently, should the Microcab concept vehicle be further optimised it is important to reconsider the structural loadpaths and investigate whether or not other means of channelling the loads through the structure would be beneficial for the structural performance and overall efficiency.

\subsection{Future topology}

The changes suggested in the above section were obtained using shape and size optimisation. The results indicated that the changes only had a minor impact on the crashworthiness of the Microcab. More drastic measures, and thus more drastic improvements may be obtained by utilising topology optimisation to extract potential vehicle structural loadpaths for a new Microcab concept vehicle. In order to do this it was necessary to create a permissible design volume wherein the loadpaths could be extracted; this is illustrated in Figure 23 and Figure 24.

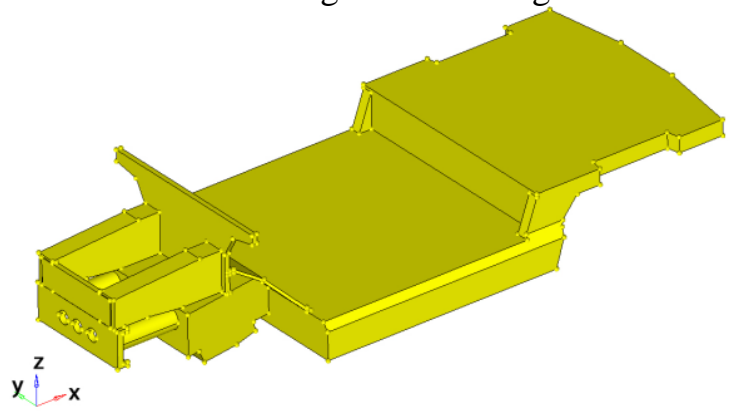

Figure 23: Microcab concept chassis design volume (top view)

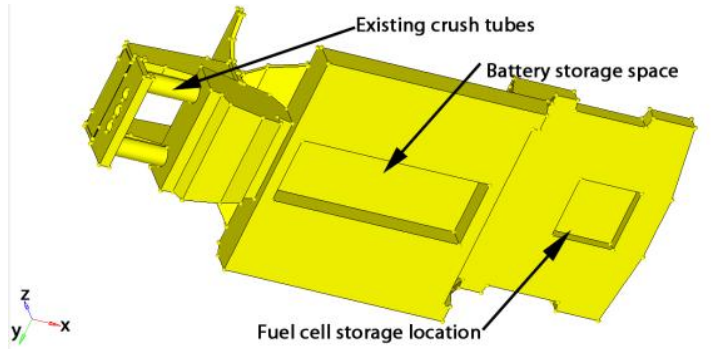

Figure 24: Microcab concept chassis design volume (bottom view)

Creating loadcases representative of the crash scenarios and the maximum crash pulse obtained from the FE (crashworthiness) analyses of section 2 , the topology optimisation could be completed. This utilised an isotropic material model and the Inertia Relief (IR) boundary conditions [7], [8], [9], [10] and [11] it was possible to extract suggestions for idealised loadpaths of the future Microcab vehicle as illustrated in Figure 25.

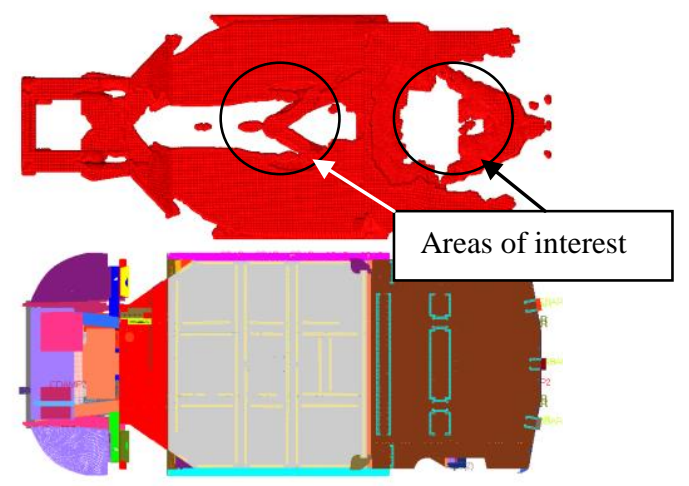

Figure 25: Optimised Design Volume Comparison

From the optimisation results, Figure 25, it may be suggested that the front-end of the current Microcab concept design does not require any significant modifications.

The centre and rear-end of the chassis looked to be the areas with the most significant and beneficial opportunities for redesign with an aim of retaining the new crashworthiness performance suggested in this paper, whilst potentially reducing the structural mass.

This paper has already addressed the rear design crash protection of the fuel cell, hence future areas of research would be the chassis floor centre where it is suggested that most of the load should be channelled along the vehicle sills and lesser through the centre of the floor. 
Future Microcab vehicles could utilise this design feature which would need to be validated via dynamic crash simulation in order to verify the impact load transfers and structural stability ahead of physical experimentation.

\section{Future Material Changes}

In addition to geometry changes a parameter which could enhance crash performance and reduce mass is the material selection. The 50 heaviest components of the Microcab have a combined mass of $465.8 \mathrm{~kg}$ and constitutes more than $2 / 3$ of the overall vehicle mass, the potential for mass reduction of these components is therefore of primary interest. The components were all individually appraised in order to determine their respective functions within the vehicle assembly as well as the potential capacity for and implications of light-weighting.

The components for light-weighting were selected using the following criteria:

- Components under high strain concentration / high-mass components identified through numeric review and simulated performance.

- Component information sanitised and classified specific to nature of part application and origin.

The possibilities of material substitution of the selected components were conducted using the following attributes:

- Generic attributes:

Material density, cost and availability of material.

- Mechanical performance based attributes:

Poisson's ratio, Young's modulus, Yield Strength.

- Unique performance based attributes: Material opacity, maximum operating temperature, durability.

- Particular production methods available specific to existing / potential materials.

The overall outcome of the material substitution study is listed in Table 3.
Table 3: Microcab suggested materials

\begin{tabular}{|c|c|}
\hline $\begin{array}{c}\text { New } \\
\text { Materials }\end{array}$ & Components \\
\hline \multirow{6}{*}{$\begin{array}{c}\text { Carbon } \\
\text { Fibre }\end{array}$} & Rear Structural Cross-member \\
\hline & Closer Floor Panel Bridge Boxes \\
\hline & Rear Axle Beam assembly \\
\hline & Rear Axle Beam assembly \\
\hline & Rear bumper assembly \\
\hline & Swing Arm \\
\hline \multirow{8}{*}{$\begin{array}{l}\text { Glass } \\
\text { epoxy }\end{array}$} & Tailgate inner \& outer \\
\hline & Roof \\
\hline & Roof inners \\
\hline & Body sides \\
\hline & Dashboard \\
\hline & Front Floor Panel \\
\hline & Battery Tray \\
\hline & Rear Floor Panel \\
\hline \multirow{3}{*}{$\begin{array}{c}\text { Polyamide } \\
\text { transparen } \\
\mathbf{t}\end{array}$} & Tailgate glass \\
\hline & Glass Quarter lights \\
\hline & Door glass \\
\hline $\begin{array}{c}\text { Magnesiu } \\
\text { m/ } \\
\text { graphite }\end{array}$ & Front Bulkhead \\
\hline $\begin{array}{l}\text { Mild grade } \\
\text { aluminium }\end{array}$ & Crush Cans \\
\hline $\begin{array}{l}\text { Mild grade } \\
\text { steel }\end{array}$ & Inner Chassis rails \\
\hline
\end{tabular}

A combination of the proposed material changes and the structurally optimised geometry from section 3.1 could be implented into the FE model to assess the overall influence of the proposed changes upon the crashworthiness of the Microcab. The results of an improved front crash peformance against a rigid wall at $40 \mathrm{~km} / \mathrm{h}$ are illustrated in Figure 26. 


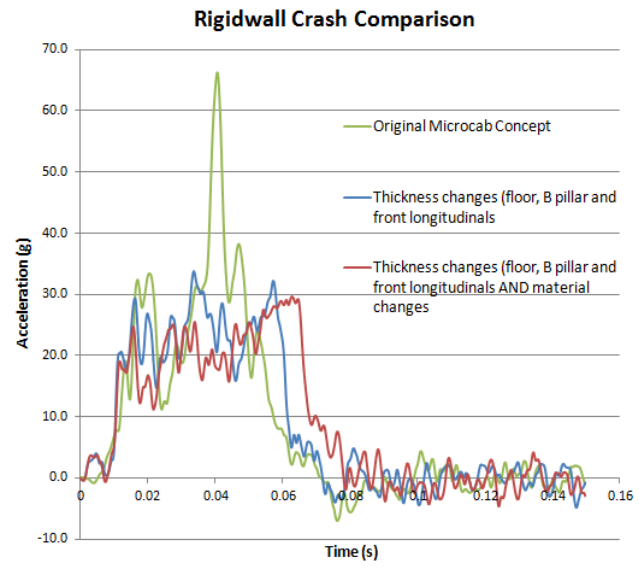

Figure 26: Microcab Concept potential structural improvements

As illustrated by Figure 26, the predicted maximum deceleration reduced from $66 \mathrm{~g}$ to $29 \mathrm{~g}$. Furthermore, the overall vehicle mass had reduced by $4 \mathrm{~kg}$ (combined geometry and material changes). Reduced Localised strain concentrations and minimised tertiary damages to interconnecting parts were observed, in addition to theoretical improved reparability across the concept vehicle Body In White (BIW).

Nevertheless, in order to further validate the impact of these suggested changes, the following aspects would also need to be addressed:

- Repeatability of manual production processes.

- Specialism / niche materials handling restricting outsourcing.

- Magnitude of capital investment to install process and equipment required.

\section{Conclusions}

Advanced numerical analysis was successfully used to optimise an already lightweight vehicle whilst simultaneously exceeding the current legislative requirements for safety and crashworthiness. The analyses included a 40 $\mathrm{km} / \mathrm{h}$ (city speed) frontal impact, compatibility studies and a rear impact scenario in which the structural integrity of the cabin, fuel cell and fuel tank were assessed.

The study concluded that the Microcab performed well in city accidents especially for front impacts. The study has also shown that using optimisation techniques it is possible to further protect the fuel cell by limiting intrusions and transfer of the bullet vehicle's momentum to the Microcab. It may also be considered to move the fuel cell towards the centre of the vehicle in order to minimise any potential damage as a consequence of intrusion.

It was suggested that the Microcab's compatibility performance, not currently a legal requirement, could be optimised by aligning the front-end crash structure height to the same level as an SUV.

Using topology optimisation, it was possible to identify areas of the vehicle for further improvements prior to a future commercial release.

The study also suggested that adhesive joints are suitable to achieve the desired structural performance including low speed damageability and higher speed crash performance.

Additional research could be conducted with a future aim of validating the crash model by refining the specific material models and perform a rigid wall impact test to confirm the modelling assembly method assumed in the current FE model is accurate, e.g. vehicle weight, chassis weight, component weight, material definitions etc..

\section{Acknowledgments}

The authors would like to thank:

- Prof. John Jostins (Director of Microcab Industries Ltd) and $\mathrm{Mr}$ Bernard Porter (Director of Low Carbon Vehicle Programmes, Coventry University) for making this student research project possible

- Liliana Cowlam of ARUP for her support and advice on non-linear explicit crash analysis using LS-Dyna

- Pascal Delannoy of UTAC for providing the computer model of the Progressive Deformable Barrier (PDB)

- V. Spirov and S. Downie, both MEng students, for their support on the Microcab concept project.

\section{References}

[1] http://www.microcab.co.uk/

[2] Fatality Analysis Reporting System (FARS). http://www.nhtsa.gov/FARS

[3] Thatcham. "Autonomous Emergency Braking" presentation. $17^{\text {th }}$ June 2011 at MIRA (Nuneaton, UK).

[4] http://www.nhtsa.gov/Research/Databases+an $\mathrm{d}+$ Software 
[5] Bastien C., Blundell M. " Influence of vehicle secondary impact following an emergency braking on an unbelted occupant's neck, head and thorax injuries International Journal of Crashworthiness", ICRASH Journal January 2013

[6] http://www.nhtsa.gov/Vehicle+Safety/Test+ Procedures

[7] J. Christensen, C. Bastien, M. V. Blundell, A. Gittens, O. Tomlin, Topology Optimisation of a Body In White for Low Carbon Technology Project, Proceedings of the European HyperWorks Technology Conference, Palais de Congres, Versailles, France, $27^{\text {th }}-29^{\text {th }}$ October 2010.

[8] J. Christensen, C. Bastien, M. V. Blundell, A. Gittens, O. Tomlin, Lightweight Hybrid Electrical Vehicle Structural Topology Optimisation Investigation Focusing on Crashworthiness, International Journal of Vehicle Structures and Systems, Volume 3, Issue 2 2011, pages 113-122.

[9] C. Bastien, J. Christensen, M. V. Blundell, M. Dickison, A. Gittens, Integration of Electric Motor and Alternator in Smart Lightweight Vehicles, Proceedings of the $4^{\text {th }}$ International Conference on Mechanical Engineering and Mechanics, Science Press USA inc., ISBN978-1-933100-40-1, August 2011, pages 921 - 931.

[10] J. Christensen, M. V. Blundell, C. Bastien, Effects of Roof Crush Loading Scenario Upon Body In White Using Topology Optimisation, International Journal of Crashworthiness, 2011.

[11] J. Christensen, M. V. Blundell, C. Bastien, Lightweight Body in White Design using Topology Shape and Size Optimisation, EVS26, Los Angeles, California, May 2012

[12] J. Christensen, C. Bastien, Generation of Optimised Hybrid Electric Vehicle Body In White Architecture from a Styling Envelope, Global Journal of Researches in Engineering

[13] J. Christensen, M. V. Blundell, C. Bastien, P. A. Batt, Buckling Considerations and Cross-Sectional Geometry Development for Topology Optimised Body In White, International Journal of Crashworthiness, 2013.

\section{Authors}

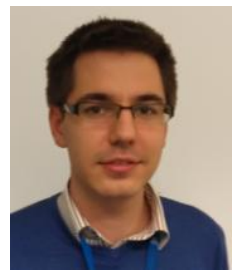

Oliver Grimes, MSc, BEng, is a Research Assistant at Coventry University, working vehicle and seat lightweighting optimisation. Oliver has started a $\mathrm{PhD}$ on lightweighting structural optimisation combined with occupant safety biomechanics.

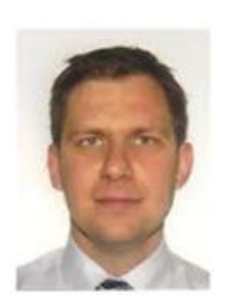

Christophe Bastien, MSc, BEng (Hons), CEng, MIMechE, FHEA, is a principal lecturer and the MSc Automotive Engineering Programme Manager at Coventry University. He has over 15 years of industrial and academic experience with FEA and crashworthiness. $\mathrm{He}$ is currently leading the research into the lightweighting of electrical vehicle architectures. He has filed 19 patents in the field of vehicle and highway engineering safety, and is currently undertaking a $\mathrm{PhD}$ in occupant biomechanics

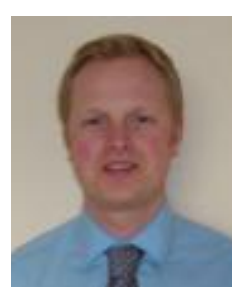

Jesper Christensen, MSc, BSc, CEng, MIMechE, FHEA, is a Lecturer in Stress Analysis at Coventry University. The past 3 years of his career has been spent focusing on structural optimisation in connection with crashworthiness, primarily in relation to HEV vehicles, for which he has published several recent papers. He is currently undertaking a $\mathrm{PhD}$ within the field of structural optimisation.

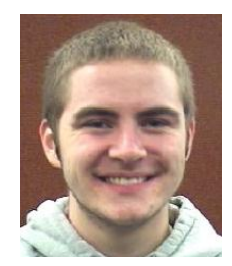

Nicholas Rawlins, Part time MEng student at Coventry University. Nicholas is employed by PLastic Omnium and expcted to complete his studies in September 2014.

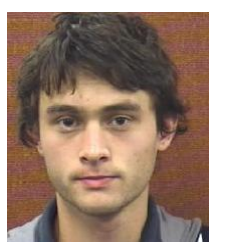

William Hammond, is a full time MEng student at Coventry University. William will graduate in June 2013. 


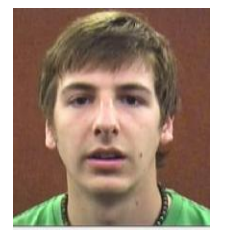

Peter Bell, is a full time MEng student at Coventry University. Peter will graduate in June 2013.

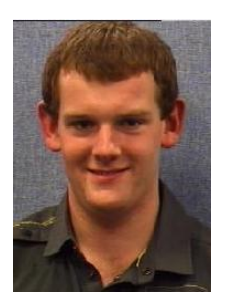

Ben Brown, is a full time MEng student at Coventry University. Ben will graduate in June 2013.

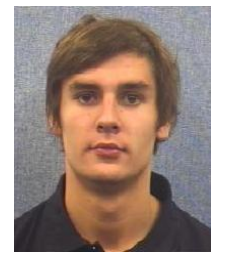

Jonathan Beal, is a full time MEng student at Coventry University. Jonathan will graduate in June 2013. 